\title{
Crack Pattern Investigation in the Structural Members of a Framed Two-Floor Building due to Excavation- Induced Ground Movement
}

\author{
Naeem Mangi \\ Department of Civil Engineering, \\ Quaid-e-Awam University of \\ Engineering, Science \& Technology, \\ Nawabshah, Pakistan \\ naeem08ce30@gmail.com
}

\author{
M. Kumar \\ Department of Civil Engineering, \\ Quaid-e-Awam University of \\ Engineering, Science \& Technology, \\ Nawabshah, Pakistan \\ manojbhoopani475@gmail.com
}

\author{
Dildar Ali Mangnejo \\ Department of Civil Engineering, \\ Mehran University of Engineering \& \\ Technology, Shaheed Zulfiqar Ali Bhutto \\ Campus, Khairpur Mir's, Pakistan \\ dildarali72@gmail.com
}

\section{Ashfaque Ahmed Jhatial}

Department of Civil Engineering, Mehran University of Engineering \& Technology, Shaheed Zulfiqar Ali Bhutto Campus, Khairpur Mir's, Pakistan ashfaqueahmed@muetkhp.edu.pk

\author{
Hemu Karira \\ Department of Civil Engineering, \\ Mehran University of Engineering \& \\ Technology, Shaheed Zulfiqar Ali Bhutto \\ Campus, Khairpur Mir's, Pakistan \\ engr.hemu07civil@gmail.com

\section{F. R. Lakhair} \\ Department of Civil Engineering, \\ Mehran University of Engineering \& \\ Technology, Shaheed Zulfiqar Ali Bhutto \\ Campus, Khairpur Mir's, Pakistan \\ faisallakhair722@gmail.com
}

\begin{abstract}
Increased urbanization causes traffic and parking issues especially in metropolitan cities like Karachi, London, Shanghai, etc. To accommodate parking issues for the vehicles mainly in urban areas (excavated) underground parking areas under or nearby high rise buildings are preferred. As a result of excavation, ground movements occur that have major impact on structures, buildings and utilities. The past research usually oversimplified surface structure as an equivalent elastic beam, which is unable to represent the behavior of a framed building realistically. In this study, the detrimental effects (i.e. crack pattern) on a two floor RCC framed building founded on piles due to an adjacent excavation-induced ground movement are investigated. Elasto-plastic coupled-consolidation analysis was adopted. The hypoplastic constitutive model was used to capture soil behavior. It is an advanced model which is able to capture the soil unique features which are non-linear behavior, stiffness degradation (with stress, strain \& path dependent), and stressstrain dependent soil dilatancy. The concrete damaged plasticity (CDP) model was used to capture the cracking behavior in the concrete beams, columns and piles. It was revealed that the induced slope and tilting are not equal. Consequently, the frame was distorted. As a result, tension cracks were induced at the inner side of the column.
\end{abstract}

\section{Keywords-excavation; RCC framed building; crack pattern}

\section{INTRODUCTION}

High rise building load is transferred to the surrounding soil through pile foundations. As a result, high stress regime is generated around the pile [1]. On the other hand, ground excavations result in ground movement due to induced-stress release [2]. With the increase in population, urbanization is also increasing, causing traffic and parking issues, especially in metropolitan cities. To accommodate parking issues, mainly in urban areas, excavations under or nearby high rise buildings are preferred. As a result, ground movements occur that have major impact on nearby structures [3]. Excavations carried out near a building may cause its distortion, affect pile foundation or even cause collapse. It is important for a geotechnical engineer to assess these dangerous situations when an excavation is carried out nearby a building. To cope with parking issues on congested cities, underground transportation systems (underground parking) have been developed. These excavations are sometimes unavoidable to be constructed adjacent to existing buildings. This condition leads to the challenge of assessing and protecting the integrity of the framed building.

Authors in [3] investigated the damage mechanism and behavior of a framed building, on shallow foundation with separate footing and different infill configuration, due to tunnelling induced ground movements, by carrying out a series of numerical analyses. They concluded that the sensitive performance of a framed building on stiffer ground is more than that on softer ground. Besides that, the infill configuration plays a significant role in the performance of a framed building. When infill walls are subjected to tunnelling caused ground movements, the structure distortion is significantly reduced. Authors in [4] investigated the effects of selected geotechnical and structural parameters on the response of masonry buildings subjected to tunnelling induced settlements. A sensitivity study has been carried out to determine the influence of building cracking and soil structure interface parameters. It was concluded that the high dependency of the 
structural response on the soil structure interface stiffness and material cracking suggests that this model could be used in extensive parametric analyses to improve the existing damage design curves. Authors in [1] carried out a sensitivity study on a $2 \mathrm{D}$ finite element model that was validated by comparing experimental results. The study investigated the effects of building weight, openings, initial damage, material properties, applied settlement profile and normal and shear behavior of base interface. The results assessed the major role played by the normal stiffness of the soil structure and the quasi brittle masonry behavior. The results showed the high dependency of the final damage to soil-structure interaction and on material cracking. Authors in [5-8, 27] reported that existing buildings affect tunnelling induced ground movement profile in a similar way as induced settlement tunnelling impacts existing adjacent buildings. Authors in [9] compared the response of different types of buildings founded on shallow foundation, which are subjected to excavation induced ground settlement, and provided a better understanding of the complex soil structure interaction in the building response. Authors in [10] suggested estimating the stiffness of framed building by simply adding separate bending stiffness of all the floor slabs. Authors in [11] carried out three centrifuge tests which were performed to study the effects of a multi propped deep excavation on the behavior of piles in dry Toyoura sand. It was concluded that lateral restraints imposed on pile head have a significant influence on the induced pile bending moment which can exceed the pile bending capacity. Authors in [12] proposed an analytical method to evaluate the reduction of capacity and increase in settlement of a nearby pile during excavation. The pile settlement due to excavation depends on the shaft friction of the pile and the soil movement pattern. Authors in [13] studied the lateral response of a pile group using a finite element method and concluded that pile bending moment and lateral deformation increase significantly with increase in excavation depth. Authors in $[29,32]$ developed design charts for the computation of the lateral behaviour of a single pile existing nearby a deep excavation in soft ground. Before carrying out the multi-strutted deep excavation, the numerical model and its soil parameters were calibrated by using the centrifuge test results and the triaxial tests reported in $[15,18]$.

The aim of this study is to give an insight into the tilting behavior and settlement of a pile group by making changes in pile length, excavation depth, supporting system stiffness, pile group distance from the excavation, permeability, initial working load, and soil state. In addition to that, the continuous changes in excess pore water pressure and long term settlement of the pile group having different positions of pile toe relative to the final exaction level are studied. Authors in [17] found that the maximum apparent earth pressure for the upper $10 \%$ of height exceeded the trapezoidal boundary of the apparent earth pressure diagrams for both soft clay and stiff clay that were initially proposed. No significant difference among the apparent earth pressure values of excavation supported by wall of different stiffness was found. Authors in [11] carried out field studies on a $10 \mathrm{~m}$ deep multi-propped excavation in overconsolidated and fissured Gault clay comparing measured and Peck's earth pressure. The measured values were near to the lower bound of Peck's chart. The strut load of the lowest prop was found to be smaller to some extent due to the low lateral stress in the ground following the construction of the diaphragm wall. Authors in [17] studied numerically a case where the clear distance between piles and the $0.8 \mathrm{~m}$ thick diaphragm wall was $3 \mathrm{~m}$. There was reasonable agreement between the measured and predicted results regarding the location of maximum deflection and bending moment. Authors in [28] concluded that computed bending moments in the steptapered piles based on upper-bound finite element results were smaller than their moment capacity, indicating that the actual moments in the piles were not large enough to cause cracking. Apart from field monitoring, this problem has been investigated by means of centrifuge modeling in soft Kaolin clay [18]. Authors concluded that the distance between pile and diaphragm wall is an important parameter which plays a major role on generated bending moment in the pile. In the presence of initial applied load, the soil surrounding the pile foundation experiences higher stress level before the starting of adjacent excavation. The excavation induced stress released in the ground induced bending moment and settlement.

Continuum numerical methods using finite-element computer programs offer powerful tools to model complex construction processes, including deep excavations. The ability to predict excavation-induced ground movements reliably, however, is wholly dictated by the input of representative parameters for the soil and the other structural components of the excavation $[6,8]$. Existing numerical codes are extremely demanding of such prior information. A practical alternative to complement numerical analysis is to discover mechanisms of behavior by means of model tests and to use them to understand the performance of buildings when subjected to excavation-induced deformations. In order to observe these mechanisms, authors in $[24,25]$ studied small-scale models tested in a $8 \mathrm{~m}$ diameter geotechnical centrifuge machine at the Cambridge University. The aim of these centrifuge tests was to simulate the excavation-soil-building interaction and to understand the mechanisms involved, rather than modeling a specific prototype. Therefore, it was decided to use sand for all the centrifuge tests due to the significantly smaller time required in preparation before testing compared to clay. An excavation system, which adopted a new technique for simulating the excavation process in-flight, was developed to investigate the interaction between soil and model buildings. The test results provided new insight into the fundamental mechanisms involved. In this paper, a detailed description of the centrifuge models (and associated test procedures) is presented followed by presentation of results from two key centrifuge tests.

Most of the previous research was focused on the damaging effects to structures founded on shallow foundation due to excavation. Surface structures were usually oversimplified as equivalent elastic beams, which does not represent the behavior of a framed building realistically. The damaging effects on piles due to excavation were rarely reported. Structural components such as piles, beams and columns were assumed as elastic. So, the main objective of this study is to estimate the crack patterns induced in the structural members due to adjacent excavation. To achieve this, three-dimensional finite element analysis (i.e. coupled consolidation parametric study) 
was conducted. The angular distortion and crack pattern in the framed building are reported and discussed.

\section{THREE-D COUPLED CONSOLIDATION ANALYSIS}

\section{A. Exacavation Description}

The $12 \mathrm{~m}$ deep exaction is carried out nearby a building at a vertical interval of $3 \mathrm{~m}$. A diaphragm wall having depth of $18 \mathrm{~m}$ with $0.6 \mathrm{~m}$ is used to support the soil mass on the excavation side. The clear distance between diaphragm and an adjacent pile is kept $3 \mathrm{~m}$. The wall penetration depth to excavation depth ratio is typically 0.5 to 2 [22], so a value of 0.5 is taken in this study. Props are used at the vertical interval of $3 \mathrm{~m}$ along the excavated soil mass to support the diaphragm wall. The props are modeled with axial rigidity of $81 \times 103 \mathrm{kNm}$ [17]. The horizontal spacing of props is $8 \mathrm{~m}$. Figure 1 illustrates the geometry of a typical case with excavation depth of $12 \mathrm{~m}$.

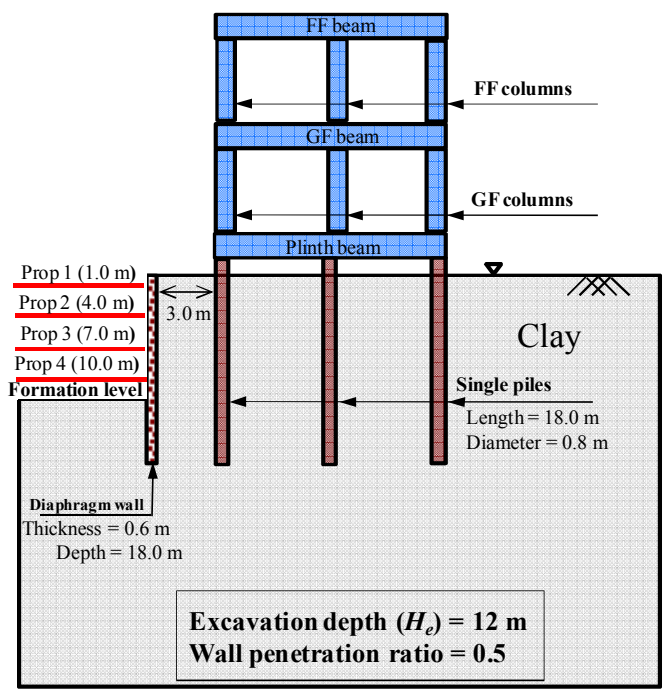

Fig. 1. Geometry of the problem adopted in this study

\section{B. Finite Element Mesh and Boundary Conditions}

Figure 2 describes the finite element mesh used in this case with size of $20 \mathrm{~m} \times 25 \mathrm{~m} \times 22 \mathrm{~m}$. In this three dimensional parametric study, solid elements (with 8-node trilinear continuum) were used to model soil, pile and diaphragm wall. Solid continuum elements are small material blocks. They can be used to build models of nearly any shape subjected to different loading because they are connected to each other like bricks in a building or tiles in a mosaic. Each node of a solid continuum element has three degrees of freedom for describing displacements in $\mathrm{x}, \mathrm{y}$ and $\mathrm{z}$ directions and one degree of freedom for taking pore pressure into account. The props were modeled by using truss elements which are long, slender structural members that can transmit only axial force but cannot transmit moment. Each truss element node has two degrees of freedom, one for displacement and one for rotation. To restrain the horizontal and vertical movement of sides, roller supports were applied. The base of the mesh was restrained in every direction by applying pin/fix supports on it. The ground water table level was taken at ground surface. At geostatic state, pore pressure distribution was taken as hydrostatic. The top of the mesh was considered drainage boundary. The frictional interface was taken between pile and soil and wall and soil. The interface was modeled by the Coulomb's friction law, in which the interface friction coefficient $(\mu)$ and limiting displacement $\left(\gamma_{\text {lim }}\right)$ are the input parameters. Interface friction coefficient of 0.35 and limiting shear displacement of $5 \mathrm{~mm}$ were assumed to achieve full mobilisation of the interface friction [19]. Excavation was carried out by deactivating soil elements within the zone of excavation. Activation of truss elements procedure was adopted for prop installation on the wall.

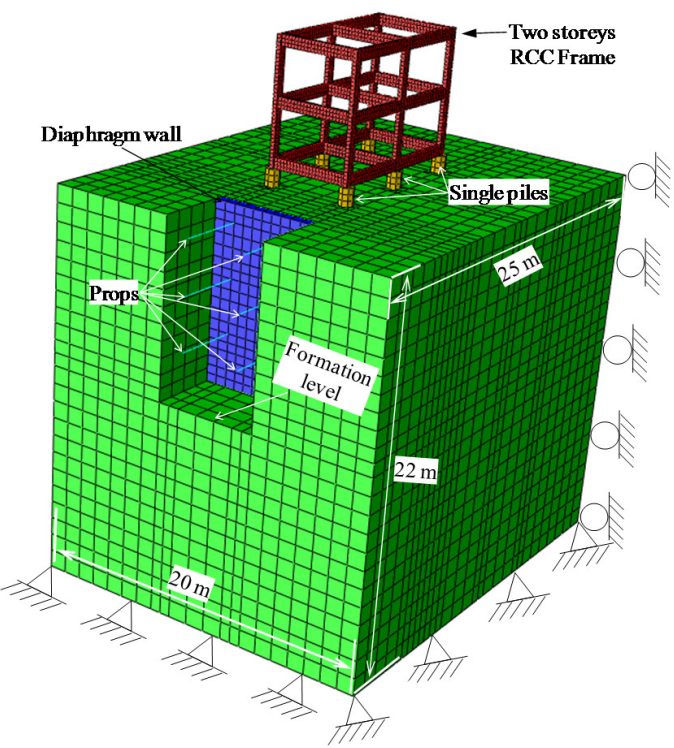

Fig. 2. Finite element mesh and boundary conditions

\section{Constitutive Model and its Parameters' Hypoplastic Model}

A hypoplastic constitutive model was used to capture soil behavior. It is an advanced model which is able to capture the unique features of soil as non-linear behavior, degradation of stiffness and stress-strain dependent dilatancy of soil. Basically nonlinear behavior within the range of strain level of medium to large (due to monotonic loading) of the granular material is captured by using the basic hypoplastic model [20-22]. There are five parameters $\left(N, \lambda^{*}, \kappa^{*}, \varphi_{c}\right.$ and $\left.r\right)$ required for the basic model. The parameters $N$ and $\lambda^{*}$ control the normal compression line location and its slope in $\ln (1+e)$ vs $\ln p^{\prime}$ diagram. Similarly, the parameter $\kappa^{*}$ is used to regulate the slope of the unloading line. The value of $r$ is responsible for controlling the large shear strain modulus. The critical state friction angle is represented by $\varphi_{c}$. Authors in [31] further implemented the concept of intergranular strain to improve the basic hypoplastic model. Moreover, five additional parameters (required by the intergranular strain) were included into the basic model for considering the strain and path dependency of soil stiffness: $R, \beta_{\Gamma}, \chi, m_{T}$ and $m_{R} . \beta_{\Gamma}$ and $\chi$ determine the rate of stiffness degradation and $R$ is an elastic range. $K_{o}$ (coefficient of lateral earth pressure at rest) was calculated by Jaky's equation:

$$
\mathrm{K}_{0}=\left(1-\sin \varphi^{\prime}\right)
$$


Hypoplastic clay model parameters are given in Table I.

TABLE I. HYPOPLASTIC MODEL PARAMETERS

\begin{tabular}{|c|c|}
\hline Description & Value \\
\hline Critical state angle, $\phi^{\prime}$ & $22^{\circ}$ \\
\hline Slope of normal compression line, $\lambda^{*}$ & 0.11 \\
\hline Slope of unloading line, $\kappa^{*}$ & 0.026 \\
\hline Position of normal compression line, $N$ & 1.36 \\
\hline Shear stiffness at medium to large strain level parameter, $r$ & 0.65 \\
\hline Initial shear stiffness with $180^{\circ}$ strain path, $m_{R}$ & 14 \\
\hline Initial shear stiffness with $90^{\circ}$ strain path, $m_{T}$ & 11 \\
\hline Elastic range, $R$ & $1 \times 10^{-5}$ \\
\hline Rate of degradation of stiffness with strain, $\beta_{r}$ & 0.1 \\
\hline Degradation rate of stiffness with strain, $\chi$ & 0.7 \\
\hline Void ratio at initial condition, $e$ & 1.05 \\
\hline Density $\left(\mathrm{kg} / \mathrm{m}^{3}\right)$ & 1136 \\
\hline Co-efficient of permeability, $k(\mathrm{~m} / \mathrm{s})$ & $1 \times 10^{-9}$ \\
\hline
\end{tabular}

\section{Concrete Damaged Plasticity (CDP) Model}

The CDP model was used to capture cracking behavior in the concrete beams, columns and piles. The CDP model provides a general capability for modeling concrete and other quasi-brittle materials in all types of structures (beams, trusses, shells, and solids). This model uses concepts of isotropic damaged elasticity in combination with isotropic tensile and compressive plasticity to represent the inelastic behavior of concrete. It can be used for plain concrete, even though it is intended primarily for the analysis of reinforced concrete structures and used with rebar to model concrete reinforcement. It is designed for applications in which concrete is subjected to monotonic, cyclic, and dynamic loading under low confining pressures.

TABLE II. ADOPTED CONCRETE PARAMETERS

\begin{tabular}{|c|c|}
\hline Description & Value \\
\hline Young's Modulus, $E$ & $35 \mathrm{GPa}$ \\
\hline Poisson's ratio, $v$ & 0.3 \\
\hline Density, $\rho$ & $2400 \mathrm{~kg} / \mathrm{m}^{3}$ \\
\hline
\end{tabular}

\section{E. Numerical Modeling Procedure}

Numerical analysis modeling procedure for a typical case is summarized as:

Step 1: Set up the initial boundary and initial stress conditions (i.e. static stress conditions with varying $K_{0}=0.63$ ).

Step 2: Activate the brick elements representing single pile (modeled as wished-in-place).

Step 3: The construction of the two-floor RCC building was carried out as follows: (a) Construct the plinth beam by activating its elements on the single piles. (b) Erect the ground floor columns on the plinth beam followed by ground floor beams by activating their elements. (c) Similarly, construct the columns and beams of the first floor of the frame.

Step 4: Allow excess pore pressure, which generated in result of application of load of the frame on the pile, to dissipate.
Step 5: Activate the brick elements representing the diaphragm wall.

Step 6: Simulate staged multi-propped excavation. After excavating to $3 \mathrm{~m}$ depth, the first level of props is installed at $1 \mathrm{~m}$ below the ground surface.

Step 7: Repeat step 6 to excavate the next stages and install props until the last stage of excavation (i.e. $H_{e}=12 \mathrm{~m}$ ) is completed.

\section{INTERPRETATION OF COMPUTED RESULTS}

\section{A. Induced Frame Angular Distortion due to Excavation}

Angular distortion (which is defined as shearing distortion of the frame) can be induced in the frame due to the adjacent excavation. Mathematically, angular distortion is calculated as:

$$
\text { Angular distortion }=\text { Slope }- \text { Tilting. }
$$

Figure 3 shows the induced angular distortion in the twofloor frame (i.e. Bay 1 and Bay 2) due to excavation-induced stress release. The horizontal axis represents the normalized excavation depth and the vertical axis shows the angular distortion induced in the Bays. The angular distortion at any vertex is taken positive if the frame is compressed diagonally at that vertex.

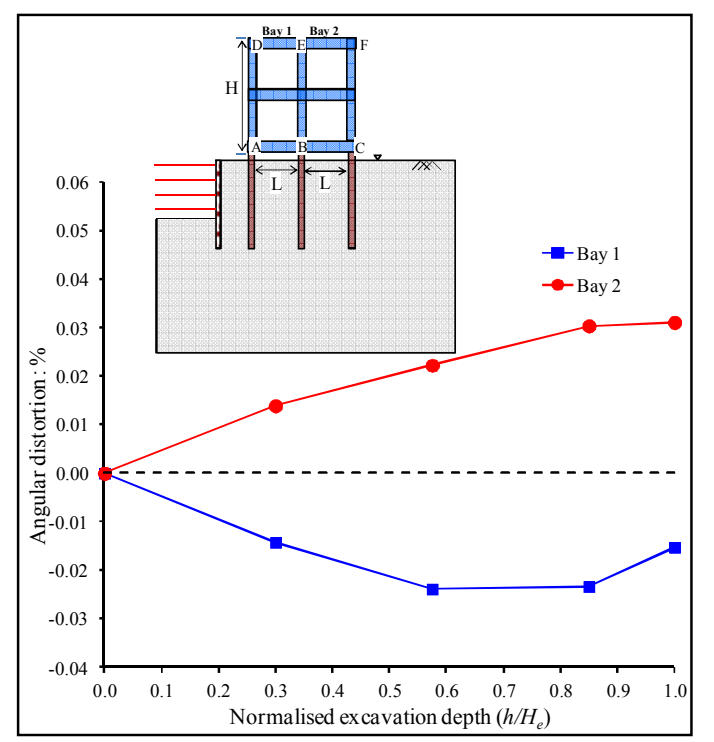

Fig. 3. Induced angular distortion in the frame due to excavation

It can be observed that negative angular distortion is induced in Bay 1 during excavation. This implies that the diagonals $\mathrm{BD}$ and $\mathrm{AC}$ of Bay 1 were stretched and compressed during excavation, respectively. This can be attributed to differential settlement and tilting of the frame due to excavation induced stress release. Consequently, the column $\mathrm{AD}$ of the frame (in Bay 1) is subjected to tension towards its inner side. As a result, the tension crack can be induced at the inner side of the column (discussed later). Unlike Bay 1, Bay 2 was distorted at vertex $\mathrm{C}$ positively during excavation. As the excavation progresses, the positive distortion at the vertex $\mathrm{C}$ of Bay 2 increases. This implies that the diagonals $\mathrm{CE}$ and $\mathrm{BF}$ of 
Bay 2 were compressed and elongated during excavation, respectively. This reason can be attributed to the differential settlement and tilting of the frame due to excavation induced stress release. Consequently, the column CF of the frame (in Bay 2) is subjected to tension towards its inner side. As a result, the tension crack can be induced at the inner side of the column (discussed below).

\section{B. Progressive Development of Tension-Induced Crack Pattern in the Frame}

As discussed above, angular distortion is induced in the frame. As a result, tension is developed in the columns of Bay 1 and Bay 2. Figure 4 illustrates the development of tensioninduced cracks (i.e. crack pattern) in the plinth beam and columns on excavation completion. For reference, the tension damage before excavation is included in the figure. The tension damage is expressed in terms of $d_{t}$ (i.e. DAMAGET) in the numerical modeling. The values of $d_{t}$ range from 0 to 1 where zero represents no damage and one complete damage in tension induced in structural member, respectively. As expected, no tension damage (DAMAGET $=0$ ) is developed in the frame before excavation. However, as excavation progresses, damage failure is induced in the plinth beam and the lower part of the ground floor columns. On excavation completion, the magnitude of scale of damage $\left(d_{\text {tmax }}\right)$ became as high as 0.97 in the bottom layer of the portion of the plinth beam resting on the pile. This suggests that the induced maximum tensile stress in that portion of the plinth beam exceeded the yield stress of the pile. Consequently, the stiffness and strength of the concrete degraded significantly.

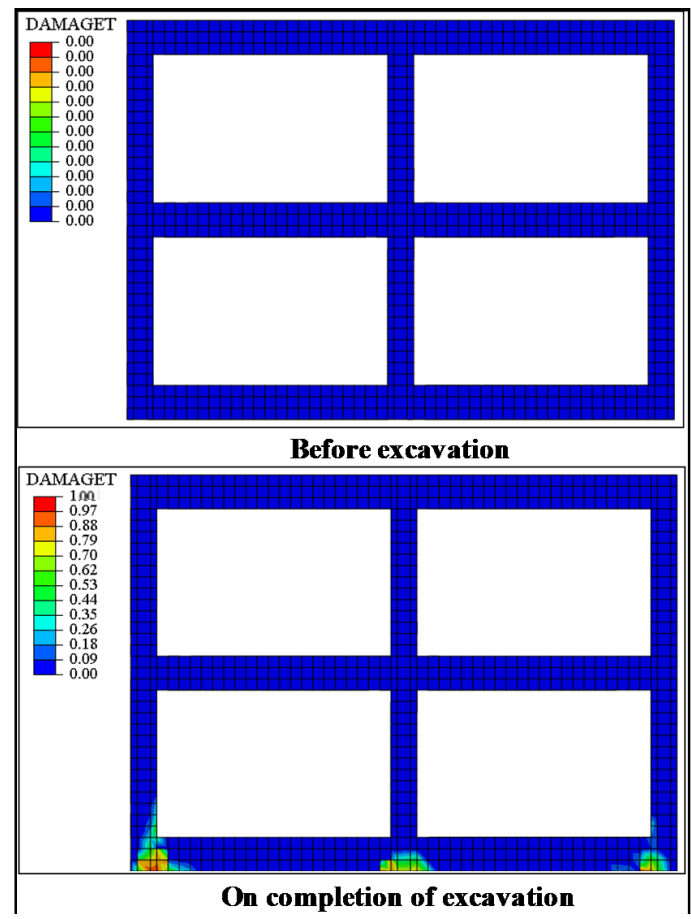

Fig. 4. Excavation-induced cracking pattern in the frame

\section{CONCLUSION}

Induced slope and tilting are not equal. Consequently, the frame was distorted. As a result, tension cracks were induced at the inner side of the column. On completion of the excavation, the magnitude of $d_{t}$ became as high as 0.97 in the bottom layer of the portion of the plinth beam resting on the pile.

\section{REFERENCES}

[1] G. Giardina, A. V. V. D. Graaf, M. Hendriks, J. G. Rots, A. Marini, "Numerical analysis of a masonry facade subject to tunnelling-induced settlements", Engineering Structures, Vol. 54, pp. 234-247, 2013

[2] H. J. Burd, G. T. Houlsby, C. E. Augarde, G. Liu, "Modelling tunnelling-induced settlement of masonry buildings", Proceedings of the Institution of Civil Engineers-Geotechnical Engineering, Vol. 143, No. 1, pp. 17-29, 2000

[3] J. Fu, Z. Yu, S. Wang, J. Yang, "Numerical analysis of framed building response to tunnelling induced ground movements", Engineering Structures, Vol. 158, pp. 43-66, 2018

[4] G. Giardina, M. A. N. Hendriks, J. G. Rots, "Sensitivity study on tunnelling induced damage to a masonry facade", Engineering Structures, Vol. 89, pp. 111-129, 2015

[5] J. N. Franzius, D. Potts, T. I. Addenbrooke, J. B. Burland, "The influence of building weight on tunnelling-induced ground and building deformation", Soils and Foundations, Vol. 45, No. 4, pp. 25-38, 2004

[6] J. N. Franzius, D. M. Potts, J. B. Burland, "The response of surface structures to tunnel construction", Proceedings of the Institution of Civil Engineers-Geotechnical Engineering, Vol. 159, No. 1, pp. 3-17, 2006

[7] J. A. Pickhaver, H. J. Burd, G. T. Houlsby, "An equivalent beam method to model masonry buildings in 3D finite element analysis", Computers \& Structures, Vol. 88, No. 19-20, pp. 1049-1063, 2010

[8] D. M. Potts, T. I. Addenbrooke, "A structure's influence on tunnellinginduced ground movements", Proceedings of the Institution of Civil Engineers-Geotechnical Engineering, Vol. 125, No. 2, pp. 109-125, 1997

[9] M. Son, E. J. Cording, "Evaluation of building stiffness for building response analysis to excavation-induced ground movements", Journal of Geotechnical and Geoenvironmental Engineering, Vol. 133, No. 8, pp. 995-1002, 2007

[10] J. B. Burland, J. R. Standing, F. M. Jardine, Building Response to Tunnelling-Case Studies from Construction of the Jubilee Line Extension, CIRIA, 2001

[11] C. W. W. Ng, M. A. Soomro, Y. Hong, "Three-dimensional centrifuge modelling of pile group responses to side-by-side twin tunnelling", Tunnelling and Underground Space Technology, Vol. 43, pp. 350-361, 2014

[12] M. Korff, R. J. Mair, F. A. F. V. Tol, "Pile-soil interaction and settlement effects induced by deep excavations", Journal of Geotechnical and Geoenvironmental Engineering, Vol. 142, No. 8, pp. 1-14, 2016

[13] D. S. Liyanapathirana, R. Nishanthan, "Influence of deep excavation induced ground movements on adjacent piles", Tunnelling and Underground Space Technology, Vol. 52, pp. 168-181, 2016

[14] N. Loganathan, H. G. Poulos, D. P. Stewart, "Centrifuge model testing of tunnelling-induced ground and pile deformations", Geotechnique, Vol. 50, No. 3, pp. 283-294, 2000

[15] T. Benz, Small-Strain Stiffness of Soils and its Numerical Consequences, $\mathrm{PhD}$ Thesis, University of Stuttgart, 2007

[16] D. E. Ong, C. E. Leung, Y. K. Chow, "Pile behavior due to excavationinduced soil movement in clay I: Stable wall”, Journal of Geotechnical and Geoenvironmental Engineering, Vol. 132, No. 1, pp. 36-44, 2006

[17] A. T. C. Goh, K. S. Wong, C. I. Teh, D. Wen, "Pile response adjacent to braced excavation", Journal of Geotechnical and Geoenvironmental Engineering, Vol. 129, No. 4, pp. 383-386, 2003

[18] D. E. L. Ong, C. F. Leung, Y. K. Chow, "Behavior of pile groups subjected to excavation-induced soil movement in very soft clay", Journal of Geotechnical and Geoenvironmental Engineering, Vol. 135, No. 10, pp. 1462-1474, 2009 
[19] C. W. W. Ng, M. A. Soomro, Y. Hong, "Effects of piggyback twin tunnelling on a pile group: 3D centrifuge tests and numerical modelling", Geotechnique, Vol. 65, No. 1, pp. 38-51, 2015

[20] D. Masin, I. Herle, "State boundary surface of a hypoplastic model for clays", Computers and Geotechnics, Vol. 32, No. 6, pp. 400-410, 2005

[21] P. W. Mayne, F. H. Kulhawy, "K0-OCR relationships in soils", Journal of the Geotechnical Engineering Division, Vol. 108, No. 6, pp. 851-872, 1982

[22] B. C. B. Hsiung, "A case study on the behaviour of a deep excavation in sand", Computer and Geotechnics, Vol. 36, No. 4, pp. 665-675, 2009

[23] S. W. Jacobsz, J. R. Standing, R. J. Mair, T. Hahiwara, T. Suiyama, "Centrifuge modeling of tunnelling near driven piles", Soil \& Foundations, Vol. 44, No. 1, pp. 49-56, 2004

[24] S. Y. Lam, Ground Movements Due to Excavation in Clay: Physical and Analytical Models, PhD Thesis, University of Cambridge, 2010

[25] M. Z. E. B. Elshafie, Effect of Building Stiffness on Excavation-Induced Displacements, PhD Thesis, University of Cambridge, 2008

[26] M. A. Soomro, D. A. Mangnejo, R. Bhanbhro, N. A. Memon, M. A. Memon, "3D finite element analysis of pile responses to adjacent excavation in soft clay: Effects of different excavation depths systems relative to a floating pile", Tunnelling Underground Space Technology, Vol. 86, pp. 138-155, 2019

[27] J. B. Burland, Assessment of Risk of Damage to Buildings Due to Tunnelling and Excavation, London Imperial College of Science, Technology and Medicine, 1995

[28] R. J. Finno, L. G. A. Monsalve, F. Sarabia, "Observed performance of the one museum park west excavation", Journal of Geotechnical and Geoenvironmental Engineering, Vol. 141, No. 1, pp. 1-11, 2014

[29] H. G. Poulos, L. T. Chen, "Pile response due to excavation-induced lateral soil movement", Journal of Geotechnical and Geoenvironmental Engineering, Vol. 123, No. 2, pp. 94-99, 1997

[30] D. Masin, J. Bohac, P. Tuma, "Modelling of a Deep Excavation in a Silty Clay", 15th European Conference on Soil Mechanics and Geotechnical Engineering, Athens, Greece, 2011

[31] A. Niemunis, I. Herle, "Hypoplastic model for cohesionless soils with elastic strain range", Mechanics of Cohesive-Frictional Materials, Vol. 2, No. 4, pp. 279-299, 1997

[32] L. Z. Wang, K. X. Chen, Y. Hong, C. W. W. Ng, "Effect of consolidation on responses of a single pile subjected to lateral soil movement", Canadian Geotechnical Journal, Vol. 52, No. 6, pp. 769782,2015

[33] D. A. Mangnejo, N. Mangi, "The responses of an end-bearing pile to adjacent multipropped excavation: 3d numerical modelling", Civil Engineering Journal, Vol. 5, No. 3, pp. 552-562, 2019

[34] D. A. Mangnejo, M. A. Soomro, N. Mangi, I. A. Halepoto, I. A. Dahri, "A parametric study of effect on single pile integrity due to an adjacent excavation induced stress release in soft clay", Engineering, Technology \& Applied Science Research, Vol. 8, No. 4, pp. 3189-3193, 2018 